\title{
Blended Learning and ICBL2013
}

http://dx.doi.org/10.3991/ijes.v2i2.3827

\author{
G. S Ferreira \\ IFSC - Instituto Federal de Santa Catarina, Florianópolis, Brasil
}

\begin{abstract}
Blended Learning or B-learning refers to a learning system where most part of the contents are transmitted in distance courses, normally by Internet, however, it includes necessarily face-to-face moments. It can comprise remote and virtual experimentation, live or interactive videos, games and other learning instruments.
\end{abstract}

This Special Issue collects an interesting set of papers describing different works in the context of B-learning.

Index Terms-Blend learning.

\section{THE EVENT}

This edition of iJES is especially dedicated to authors who presented their work in ICBL2013 (International Conference on Interactive Computer aided Blended Learning) and they were selected because of their important contributions in this area.

The ICBL is an event that is part of a series of events, which are coordinated by IAOE International Association of Online Engineering. The first edition of the ICBL was held in Florianópolis-Brazil, in 2007 on the premise to decentralize discussions in the area of computermediated education, allowing teachers and researchers in the Latin America to publish their work in an international level, with a minimum of travel efforts.

After the first ICBL, several educational institutions from LA have consolidated their interest in Blended Learning. It was organized in 2008 and 2009 in Florianópolis again, in 2011 in Guatemala and in 2013 again in Florianópolis.

The main objective of this event is to disseminate, discuss and develop issues related to teaching techniques combined with the use of various educational technologies at various levels. To achieve these goals, there were more than 160 submissions of papers and about $65 \%$ of them were selected by the Program Committee to be presented as Keynote Speeches, workshops, posters and oral presentation of papers in Portuguese and English sessions. Participants from several Brazilian states and more than 10 countries gave us an excellent representation and diversity of ideas, cultures and procedures. It was a great moment for teachers, researchers and students to meet and discuss topics in the area of computer aided education.

Nowadays, our students are native digital that means they were born after the development of several communication technologies resources. They are different from young people years ago, who are the digital immigrants. They have strong characteristics of multiple and simultaneous access to different medias. They are multilingual and they have multiple options and access to the technology and information.

The facilities that the media and the Internet give to us also reveal that the lessons and the teaching methods need to change and to have some kind of differential to keep the attention and interest of these students.

Blended Learning or B-Learning is a very appropriate concept in this context, where most part of the content is transmitted at a distance, but necessarily includes classroom meetings, hence the origin of the blended name as something mixed, combined. 


\section{FINAL REMARKS}

Special thanks to the Vice-Chairman of the Conference, Prof. Andreas Pester, one of the creators of the event, to the members of the Program Committee, composed by more than 40 researchers from 17 countries and to the Keynote Speakers: Prof. Françoise Trapenard from Fundación Telefónica, Brazil; Prof. Andreas Pester from Carinthia Tech Institute, Austria; Prof. Matthew Broda from College of Wooster, USA; Prof. Caterina Berbenni- Rehm from Promis, Luxemburg; and Prof. Carlos de Castro Lozano from Universidad de Córdoba, Spain.

The event was a success also because of our major sponsors and supporters: IFSC - Instituto Federal de Santa Catarina as organizer and main sponsor, represented by the Magnificent Rector, Prof. Maria Clara Kaschny Schneider; IFC - Instituto Federal Catarinense, UFSC - Universidade Federal de Santa Catarina, UDESC - Universidade do Estado de Santa Catarina, IAOE International Association of Online Engineering, and FAPESC - Fundação de Amparo à Pesquisa e Inovação do Estado de Santa Catarina.

\section{AUTHOR}

G. S. Ferreira is with IFSC - Instituto Federal de Educação, Ciência e Tecnologia de Santa Catarina and he was the General Chairman of ICBL2013. Rua 14 de Julho, 150 - Coqueiros, Florianópolis, Santa Catarina, Brasil CEP $88075-$ 010 (golberi@ifsc.edu.br). 